\title{
Belonging, connectedness and social exclusion
}

\section{Beth R Crisp}

Deakin University

\begin{abstract}
Promoting connectedness and/or a sense of belonging are strategies used in addressing social exclusion. While belonging and connectedness are often used interchangeably, this paper demonstrates that while they may be co-existent, it is equally possible to have one without the other. Hence, this paper contends that these two concepts need to be carefully distinguished by those planning and delivering social work services. Furthermore, consideration of both connectedness and belonging enables a more nuanced understanding of social exclusion which challenges the assumption that inclusion and exclusion are binary opposites, and that it is possible to be both included and excluded at the same time.
\end{abstract}

Keywords: Belonging, connectedness, social exclusion, social inclusion

Understandings of social exclusion have broadened from originally being closely associated with economic factors to recognise a wider range of restrictions which limit participation in social or cultural arenas which the majority of the population takes for granted (Taket et al., 2009). For those who endure inequalities which are seemingly unable to be overcome, a sense of 'dismemberment' (Scanlon \& Adlam, 2008, p. 529) or of no longer belonging in the mainstream of society becomes a very real possibility. There has been also been a growing recognition that profound alienation of segments of the community is neither in the best interests of the individuals concerned nor of civil society and this has been the impetus for the establishment of a range of social interventions (Taket et al., 2009).

Irrespective of how social exclusion has been defined, persons and communities who are socially excluded form the majority of users of social work services, and an understanding of social exclusion can assist social workers make sense of the often profound feelings of alienation which they may encounter regularly in their work: 
The concept of social exclusion attempts to help us make sense out of the lived experience arising from multiple deprivations and inequities experienced by people and localities, across the social fabric, and the mutually reinforcing effects of reduced participation, consumption, mobility, access, integration, influence and recognition. The language of social exclusion recognises marginalising, silencing, rejecting, isolating, segregating and disenfranchising as the machinery of exclusion, its processes of operation. (Taket et al., 2009, p. 3)

Social work responses which seek to address social exclusion are often unclear as to whether the aim is to promote a feeling of belonging or enhance the sense of connectedness for participants. This paper contends that although belonging and connectedness often coexist, it is necessary to understand the differences between these states and not to assume they are synonymous. Hence, after defining both belonging and connectedness, this paper will explore a range of relationships between them.

\section{Belonging}

Most people have an inherent need to feel they belong and experience varying degrees of belonging in a range of relationships, settings and places, or believing there to be others with whom we share a viewpoint. These may include families, friendship groups, religions, sporting clubs, political or social movements, places of work or learning, local communities or whole nations (Crisp, 2010). Belonging may be formalised with members identified as those who have been party to some form of contract, paid fees and/or undergone some ceremony of initiation or welcome. However belonging doesn't necessarily require formalisation, and even when processes of formalisation have occurred, a sense of belonging may not ensue. Furthermore, people don't always feel they readily belong in the places or groups where one might imagine they fit, or they may feel they belong in situations in which they might readily be considered to be an outsider (Rochford et al., 2008).

Belonging necessarily creates a situation of insiders and outsiders. Belonging involves becoming an insider within a group, organisation or a somewhat less structured network of people with common attributes or beliefs. Insiders may become privy to "secrets" kept from the wider world (Bradley, 2009) and indeed may not even realise such secrets exist until such time as they are no longer deemed outsiders by the in-group (McGirr, 2004).

Belonging is not necessarily something people actively consider except at points of crisis or when they stumble into a new experience of belonging. Nevertheless, some level of belonging is a constant requirement, providing a sense of surety in order to be oneself, and to face the risk of rejection or failure which emerges when we set out on new enterprises, meet new people or go to new places (Callaghan, 1998).

\section{Connectedness}

Whereas belonging is associated with subjective notions of identity (Furlong, 2003; Ward, 2009), connectedness relates more to participation in societal organisations or social networks. It has been claimed that "the language of social connectedness recognises acceptance, opportunity, equity, justice, citizenship, expression and validation as the machinery of connectedness" (Taket et al., 2009, pp. 3-4). However it is possible to be connected but not feel any of the emotional attachment which is associated with belonging.

Many social workers, especially those involved in groupwork or community development initiatives, are often involved in programs which aim to enhance the sense of 
connectedness for participants, that is increasing the numbers of people they know and/or the number of organisations with which they meaningfully relate. Hence, connectedness refers to the number and strength of connections which potentially could be measured (Standsfeld, 2006).

\section{The relationship between belonging and connectedness}

Reflection on the literature about belonging and connectedness, suggests at least four different forms of association between belonging and connectedness: connectedness as a precursor to belonging, connectedness reinforcing belonging, connectedness but not belonging, and belonging without connectedness. Each of these will be discussed in turn.

\section{Making connections as a precursor to belonging}

Becoming involved in community groups or organisations is one way of establishing one's identity in a complex and fragmented society (Lynch, 2007). While social norms within a family or friendship group can provide strong motivation to make particular connections (Bellamy et al., 2002; Evans \& Kelley, 2004), for some it may be more important to seek out others with like interests or viewpoints. However there may well be a gulf to be crossed after making connections before feeling one truly belongs.

One of the signs by which others let you know that they believe you belong is how they greet you. Titles may give way to first names or in some instances polite greetings may be traded for affectionate greetings which might readily be perceived as insults by outsiders:

Even when friends are greeted they are often subjected to verbal scorn and abuse, sworn at and called names, and all in the spirit of friendship. If you really like someone, you heap a lot of gentle abuse upon him or her, to show him or her that you care so much. If you don't like someone, you are often very polite and affable, because as yet there is no basis upon which to launch into the friendly banter ... (Tacey 2009, p. 47)

Conversely, bullying, teasing, taunting, being made fun of by one's peers or connections can be ways of telling someone that they don't belong (Hendry \& Reid, 2000). The desire to be seen by others as belonging, may see individuals yielding to group pressures. The following finding from a study of rural Scottish youth, some of whom experienced bullying and teasing, could relate to many others:

Fitting in was part of the larger group of skills needed to "get along" and be able to handle life situations in general. Thinking about what might inoculate a person or make him more vulnerable was common. Complying with a basic set of social standards in appearance, especially dress and behaviour, was a typical tactic to prevent criticism and teasing. Conformity gave one both a defence against certain types of trouble and a gesture towards acceptance. (Hendry \& Reid, 2000, p. 711)

It is not just at the interpersonal level that people choose to become connected to people or situations where they feel the potential to belong. In the UK (and undoubtedly this applies also in North America and Australasia), the concept of a "normal" university student is someone not long finished secondary school, white, middle or upper class and who speaks English as their first language. Potential students who do not fit this profile disproportionately 
seek places in the less elite British universities which have the highest proportions of "nontraditional" students like themselves. This reflects a desire to study in an institution where they believe there will be others like them to connect with and that there is some possibility of them feeling they belong (Read et al., 2003).

It is unclear whether it is the number of connections, or the strength of the connections one has, that results in a sense of belonging. For example, it has been suggested that the more connections one has, the greater the likelihood of unemployed persons gaining employment and reducing the potential for exclusion in the wider community (Ngai et al., 2008). However, others would suggest the quality of one's friendships is more important than the number of friends as a preventive measure against social exclusion (Wong, 2006).

\section{Maintaining connections reinforces a sense of belonging}

Communities which have high levels of poverty, crime and family breakdown, along with low levels of employment tend to be characterised only in terms of overall levels of disadvantage without recognition of positive features of the community. A recent study of young adults in the Teeside region of England provides a pertinent reminder as to why this approach is problematic. Teeside emerged as a major centre of industry in the $19^{\text {th }}$ century but in recent times has suffered very high levels of unemployment as the result of one quarter of all jobs, and half of all manufacturing and construction jobs in the region disappearing in the 1970s and 1980s. While there is no denying that for many young adults in Teeside frequent periods of unemployment are a feature of their lives, they are not disconnected but rather maintained strong connections with their communities, with no question that they did not belong. In particular the researchers noted:

The neighbourhoods and people we studied were relatively rich in terms of supportive social networks of family and friends and bonding capital. Subjectively, informants stressed their strong sense of place attachment, of community and of social inclusion, not exclusion. Informants came from - and were included in - a locally embedded ... working community. (McDonald, 2008)

Another example of how maintaining connections contributes to an ongoing sense of belonging can be found in the social arrangements often observed in migrant communities. Migration, whether chosen or forced, creates considerable potential for disconnection with one's past, with the importance of these connections only becoming recognisable once one has moved away (hooks, 2009). For those for whom where they come from is fundamental to their sense of identity, maintaining connections with their origins, either directly or indirectly through maintaining cultural links, can reinforce a sense of belonging. Consequently organisations which contribute to the forging and maintenance of social and cultural ties for ethnic minorities are often claimed to be the most important institutions for their members. This includes ethnospecific religious organisations, of which for a substantial proportion of their membership, participation may be more a matter of maintaining cultural links than opportunities for religious expression (Pui-Lan, 2006). Connecting with others in such organisations may be important not just for migrants but also for their descendants. Subsequent generations of migrants can be left in a state of limbo, especially those whose looks and name betray the family's origins, but for whom those origins are little more than stories they have spent their life listening to (Brady, 2007). Hence, organisations which connect migrants and their families provide a core for the community, for both individuals and the community to develop and maintain their cultural identity, provide support in times 
of difficulties and disappointments, and promote health and wellbeing (Este \& Bernard, 2006).

\section{Connected but not belonging}

Being connected may frequently be sufficient but even those who are seemingly wellconnected can fear loneliness and/or isolation which are associated with feelings of not belonging. Interviews with service users who were dying or bereaved have revealed that one of the most important things for such individuals is knowing that there were family and friends who cared about them (Lloyd, 1997). Although such caring relationships may have emerged through mutual participation in various groups or organisations, merely joining a group is no guarantee that such levels of belonging will emerge.

It can be difficult to feel a sense of belonging even in settings which are ostensibly open to all members of the community. One of the criticisms sometimes applied to religious and charitable organisations is that they have become middle class clubs which are seemingly much more concerned with maintenance of establishment values than championing the needs of the most deprived and excluded members of society, who may not be made to feel welcome and even encouraged to leave. For example, single mothers have been made to feel they don't belong in some contexts which are supposedly "family focused", but have a narrow view as to what "family" means (Tomlinson 1995).

Just as explicit disapproval of particular characteristics including values and lifestyles can result in people not feeling they belong, so too can the failure to recognise the existence of particular segments of the community and their particular needs or issues. One group for whom this applies are young people who are bisexual:

Bisexual-identifying or bisexual-behaving young people are both 'outside' (excluded from) heteronormative and 'homonormative' constructs of sexual binaries, and yet 'belonging' (included) in the sense that they may 'pass' as a 'normal' heterosexual or 'normal' homosexual. Subsequently, they are 'outside' (excluded from) the dominant constructs of gay community and heterosexual society in Australia while simultaneously 'belonging' (included) due to their same-sex and opposite-sex attractions and relationships. (Martin \& Pallotta-Chiarolli, 2009, p. 143)

As one young person explains:

It's like we're the X-files or something. We're not straight A files or gay B files. It's like we mess up their [gay and straight communities'] tidy sex files. But that means they make you feel like you're messed up yourself, as if there's no way their filing system is what's really fucked. (Marita, adolescent research participant in Martin \& Pallotta-Chiarolli, 2009, p. 143)

Another group who are not usually considered to be excluded, and who in some domains may be well connected but who often feel that in the wider society they don't readily belong, are women who have chosen to be childless and have a career. When there is a dominant ideology that choosing not to be a mother represents deviance, selfishness and even a failure to do one's duty to the nation by contributing to the production of the next generation, women who make such a choice are often made to feel they belong only with the minority of others like themselves (Carey et al., 2009).

Being connected but not belonging is problematic, as in the above examples, when one's sense of identity is violated or invalidated. Nevertheless, there may be many others - 
individuals, groups or organisations, with which one has connections, which may be strong and meaningful, but which don't generate a sense of belonging, and indeed one may not want to belong to.

\section{Belonging but not connected}

Some people make a choice to limit their connections with others as a strategy to feeling a sense of belonging in a diverse community. The American cultural critic bell hooks observed this phenomenon among those around her when she found herself living in New York City:

New York City was one of the few places in the world where I experienced lonelinesss ... I attributed this to the fact that there one lives in close proximity to so many people engaging in a kind of pseudo intimacy but rarely genuine making community. To live in close contact with neighbours, to see them every day but to never engage in fellowship was downright depressing. People I knew in the city often ridiculed the ideas that one would want to live in community - what they loved about the city was the intense anonymity, not knowing and not being accountable. (hooks, 2009, p. 24)

Historically, length of participation has been regarded as predictive of a sense of belonging to a particular community on the basis that those who are long-established are more likely both to be more involved in community activities and have larger social networks (Sampson, 1991). However urban renewal can lead to situations in which older people, despite their long tenure may become very isolated and alienated from their local communities. In one commentary on gentrification in part of Manchester, it was observed that:

... there is no sense of a past, historic, community that has moral rights on the area: rather the older working-class residents, when they are seen at all, are seen mainly as residues. (Savage, Bagnall \& Longhurst, 2005, p. 44)

Even if they wanted to, long-term elderly residents may find it hard to connect with newcomers, in areas which have been gentrified. Typically the newcomers will be much younger and living a very different lifestyle associated with having far greater financial resources. The presence, let alone the needs, of older people in their midst can readily go unrecognised (Phillipson, 2007).

If belonging can occur when any sense of connectedness with others has been dismantled, it can equally emerge for those who have never had a clear sense of connection with other members of a community or even an intention to become connected with others. Sometimes referred to as "elective belonging":

Individuals attach their own biography to their 'chosen' residential location, so that they tell stories that indicate how their arrival and subsequent settlement is appropriate to their sense of themselves. People who come to live in an area with no prior ties to it, but who can link their residence to their biographical life history, are able to see themselves as belonging to the area. (Savage et al., 2005, p. 29)

Hence, a sense of belonging can emerge prior to strong or indeed any connections being made. For example, in a study of single mothers who were welfare recipients, "Vicky" reported a much greater sense of belonging as she moved to a low income suburb where she felt "normal" from a much wealthier area where she was unable to "fit in": 
[Low-income Suburb]'s quite a good area to be poor in! Although there is sort of some money around, but generally people aren't as superficial. Yeah, or aren't as judgemental about that sort of thing as they are in other places. A lot of people here are the working class kind, in the suburbs. So I don't feel, you know, that disadvantaged. Although when I lived in [High-income Suburb] before I moved over to this side of town, I did feel it a lot more there. (Vicky, in Cook, 2009, pp. 60-61)

Similarly, a mature age student in her first year of studying at one of Scotland's ancient universities recalls:

When I was in the [oldest building] sitting in the lecture theatre you're kind of thinking 'I wonder who sat here before me', you know there's a wonderful sense of history about the place. (in Christie, Tett, Cree, Hounsell \& McCune, 2008, p. 573)

For this student, a sense of belonging came not from interactions with fellow students, but from the sense of achievement of having been admitted to a prestigious university in which the proportion of students from disadvantaged backgrounds is low. However, rather than reinforcing a sense of belonging, interactions with other students had the potential to diminish belonging. As another student in the same study commented:

I know that the way that I speak is working class and I have got an accent, and being in an environment where there is lots of middle and upper class students and when they are presenting, and they are able to project themselves, it just seems to be a completely different thing for me, because I suppose I am class conscious ... and I didn't feel very confident in front of middle and upper class people because I know that I carry an accent. (in Christie et al., 2008, p. 578)

A sense of disconnection combined with a desire for belonging is evident in the emergence of virtual communities, particularly those which utilise the internet (Cheng, 2006). While the internet has the potential to enable direct connections to be made with similar others, sensing that there are like others out there somewhere, may in itself lead to feeling a sense of belonging to a virtual community. Nevertheless, actively fostering a sense of belonging through making amorphous connections is not without controversy (Simmonds, 2000). Whether participation in a virtual community signifies connectedness is debatable, and perhaps this depends on the forms of participation. Arguably there might be a stronger rationale for suggesting that participation in interactive forums, whether these are synchronous or asynchronous, fits better with the proposition that connectedness leads to belonging. However, for those who "lurk" or follow communications passively, one might well contend that belonging without connectedness is possible.

\section{Discussion}

This paper has sought to distinguish connectedness and belonging and concludes that while these may be co-existent or there may be a causal association between them, both connectedness and belonging can also exist alone without the other. This distinction is important for social workers and other professionals involved in the planning and delivery of programs designed to address social exclusion. For example, it should not be assumed that a program which aims to increase connectedness will necessarily result in participants feeling a greater a sense of belonging or vice versa.

Consideration of both connectedness and belonging provides the potential for a more nuanced understanding of social exclusion which challenges the assumption that inclusion 
and exclusion are binary opposites, that one is only ever included or excluded (cf. Sheppard, 2006). As many of the examples in this paper demonstrate, the reality for most people is they live concurrently with experiences of inclusion as well as exclusion (Pease, 2009). Within social work, this applies equally to service users as to social workers, recognising that in some contexts service users may become service providers (Meeuwisse, 2008). Recognising belonging and social connectedness as two distinct, although often related, concepts which are in opposition to social exclusion enables social exclusion to be understood as a dynamic rather than necessarily fixed state of existence (Savage \& Carvill, 2009). Nevertheless, for this to occur, policy and practice agendas need to ensure that connectedness is not promoted to the extent that recognition of the need for belonging is minimised or lost altogether or vice versa. For example, an access and equity program which builds connectedness by attracting disadvantaged students into higher education but does not address issues of alienation or a sense of not belonging after these students have commenced studying, is likely to have difficulties retaining them in their courses until graduation (Read, Archer \& Leathwood, 2003). Conversely, a media campaign which attempts to promote pride in one's local community, to promote a sense of belonging, may have limited effectiveness if there are not adequate opportunities for members of the community to meet and engage with each other in meaningful ways, in other words, to build connectedness (Crisp, 2000).

It must be conceded that conceptualising connectedness and belonging in opposition to social exclusion is not entirely unproblematic. The recognition of many individuals and groups either feeling they don't belong or do not have meaningful connections in their communities, may greatly increase the proportion of the population considered to be experiencing social exclusion. However, this has the potential to deflect attention of policy makers and service providers away from the most disadvantaged sectors of the community (Meeuwisse, 2008). Nevertheless, it may well be a reasonable expectation that those who endure significant disadvantage are among those who no longer believe they belong in the wider society (Scanlon \& Adlam, 2008).

\section{References}

Bellamy, J., Black, A., Castle, K., Hughes, P. \& Kaldor, P. (2002). Why People Don't Go to Church. Adelaide: Openbook Publishers.

Bradley, J.J. (2009). Not to generalise: The "sacred" in Yanyuwa country. In M. Paranjape (Ed.), Sacred Australia: Post-secular considerations. Melbourne: Clouds of Magellan.

Brady, V. (2007). Disconnection. In F. Gale, N. Bolzan \& D. McRae-McMahon (Eds.), Spirited Practices: Spirituality and the helping professions. Crows Nest NSW: Allen \& Unwin.

Callaghan, B. (1998). What does it mean to belong? The Way, 38, 108-116.

Carey, G.E., Graham, M., Shelley, J. \& Taket, A. (2009). Discourse, power and exclusion: The experiences of childless women. In A. Taket, B.R. Crisp, A. Nevill, G., Lamaro, M. Graham \& S. Barter-Godfrey (Eds.), Theorising Social Exclusion. Abingdon: Routledge.

Cheng, P.S. (2006). Reclaiming our traditions, rituals and spaces: Spirituality and the Queer Asian Pacific American experience. Spiritus, 6, 234-240.

Christie, H., Tett, L., Cree, V.E., Hounsell, J.\& McCune, V. (2008). 'A real rollercoaster of confidence and emotions': Learning to be a university student. Studies in Higher Education, 33, 567-581.

Cook, K. (2009). Not measuring up: low-income women receiving welfare benefits. In A. Taket, B.R. Crisp, A. Nevill, G., Lamaro, M. Graham \& S. Barter-Godfrey (Eds.), Theorising Social Exclusion. Abingdon: Routledge.

Crisp, B.R. (2000). Media advocacy. Health Promotion Journal of Australia, 10, 105-107.

Crisp, B.R. (2010). Spirituality for Social Workers. Farnham: Ashgate.

Este, D. \& Bernard, W.T. (2006). Spirituality among African Nova Scotians: A key to survival in Canadian society. Critical Social Work, 7, 1. 
Evans, M.D.R. \& Kelley, J. (2004). Religion, Morality and Public Policy in International Perspective 19842002. Annandale: The Federation Press.

Furlong, M. (2003). Critiquing the goal of autonomy: Towards strengthening the 'relational self' and the quality of belonging in casework practice. European Journal of Social Work, 6, 5-18.

Hendry, L.B. \& Reid, M. (2000). Social relationships and health: The meaning of "connectedness" and how it relates to health concerns for rural Scottish adolescents. Journal of Adolescence, 23, 705-719.

hooks, b. (2009). Belonging: A Culture of Place. New York: Routledge.

Lloyd, M. (1997). Dying and bereavement, spirituality and social work in a market of welfare economy. British Journal of Social Work, 27, 175-190.

Lynch, G. (2007). The New Spirituality: An introduction to progressive belief in the twenty-first century. London: I.B. Tauris and company.

McDonald, R. (2008). Disconnected youth? Social exclusion, the 'Underclass’ \& economic marginality. Social Work and Society, 6, 2.

McGirr, M. (2004). Bypass: The story of a road. Sydney: PanMacmillan Australia.

Martin, E. \& Pallotta-Chiarolli, M. (2009). "Exclusion by inclusion”: bisexual young people, marginalization and mental health in relation to substance abuse. In A. Taket, B.R. Crisp, A. Nevill, G., Lamaro, M. Graham, \& S. Barter-Godfrey (Eds.), Theorising Social Exclusion. Abingdon: Routledge.

Meeuwisse, A. (2008). Organizational innovation in the Swedish welfare state. Critical Social Policy, 28, 187210.

Ngai, S.S., Ngai, N., Cheung, C. \& To, S. (2008). The effects of service participation, friendship networks, and family support on developmental outcomes: A study of young people from low-income families in Hong Kong. Adolescence, 43 (170), 399-416.

Pease, B. (2009). The other side of social exclusion: interrogating the role of the privileged in reproducing inequality. In A. Taket, B.R. Crisp, A. Nevill, G., Lamaro, M. Graham, \& S. Barter-Godfrey (Eds.) Theorising Social Exclusion. Abingdon: Routledge.

Phillipson, C. (2007). The 'elected' and the 'excluded': Sociological perspectives on the experience of place and community in old age. Ageing and Society, 27, 321-342.

Pui-Lan, K. (2006). Introduction. Spiritus, 6, 217-220.

Read, B., Archer, L. \& Leathwood, C. (2003). Challenging cultures? Student conceptions of 'belonging' and 'isolation at a post-1992 university. Studies in Higher Education, 28, 261-277.

Rochford, T., Belanger, P. \& Villanueva, D. (2008). Conversation with Adolfo Nicolas. The Way, 47(3), 9-29.

Sampson, R.J. (1991). Linking the micro- and macrolevel dimensions of community social organization. Social Forces, 70(1), 43-64.

Savage, M., Bagnall, G. \& Longhurst, B. (2005). Globalization and Belonging. London: Sage.

Savage, S. \& Carvill, N. (2009). The relationship between undertaking an informal caring role and social exclusion. In A. Taket, B.R. Crisp, A. Nevill, G., Lamaro, M. Graham, \& S. Barter-Godfrey (Eds.), Theorising Social Exclusion. Abingdon: Routledge.

Scanlon, C. and Adlam, J. (2008). Refusal, social exclusion and the cycle of rejection: A cynical analysis? Critical Social Policy, 28, 529-549.

Sheppard, M. (2006). Social Work and Social Exclusion: The idea of practice. Aldershot: Ashgate.

Simmonds, G. (2000). Traditions of spiritual guidance: Spiritual direction in cyberspace, The Way, 40(3), 263271.

Standsfeld, S.A. (2006). Social support and social cohesion. In M. Marmot \& R.G. Wilkinson (Eds.), Social Determinants of Health, ( $2^{\text {nd }}$ ed.). Oxford: Oxford University Press.

Tacey, D. (2009). Spirituality in Australian today. In M. Paranjape (Ed.), Sacred Australia: Post-secular considerations. Melbourne: Clouds of Magellan.

Taket, A., Crisp, B.R., Nevill, A., Lamaro, G., Graham, M. \& Barter-Godfrey, S. (Eds.) (2009). Theorising Social Exclusion. Abingdon: Routledge.

Tomlinson, D. (1995). The Post Evangelical. London: SPCK.

Ward, N. (2009). Social exclusion, social identity and social work: Analysing social exclusion from a material discursive perspective. Social Work Education, 28, 237-252.

Wong, H. (2006). Human capital, social capital and social exclusion: Impacts on the opportunity of households with youth to leave poverty. International Journal of Adolescent Medicine and Health, 18(3), 521-534. 


\section{Biographical Note}

Beth R Crisp is Associate Professor of Social Work in the School of Health and Social Development at Deakin University. Her recent publications include Spirituality and Social Work (Ashgate 2010) and Theorising Social Exclusion (Routledge 2009) which was jointly written by a group of staff from the School of Health and Social Development at Deakin. 